\title{
Blue Whale Challenge: Perplexing the teens' minds
}

\author{
Tanu Anand ${ }^{1}$, Jugal Kishore ${ }^{2}$
}

With advent of progress in internet communication and online gaming, the use of internet has increased considerably amongst adolescents. ${ }^{1}$ The utilization has risen to such an extent that it has become pathological and 'Internet Gaming Disorder' has been included in the latest edition of the Diagnostic and Statistical Manual of Mental Disorders (DSM-5) as a condition meriting further research. ${ }^{2}$ Though there is ample evidence stating the psychological consequences of playing online games and getting 'hooked to them', taking one's life or committing suicide presents the extreme behavior of an adolescent perplexed with the online challenge.

The online and WhatsApp game market is flourishing rapidly. Games on death or dying are available for children such as Dumb ways to Die, Die in 100 ways, 1000 ways to die in a circle, kill yourself, etc. Some may be for fun but title of games sound threatening. There is whole lot of deadly games (like choking game, huffing, car surfing etc.) that the teens are playing today. The latest addition to this list is a game known as "Blue Whale Challenge". This sinister online game, brainwashes the players particularly young children, into committing suicide. When a player signs up for the game, he or she is assigned with 50 daily tasks that they need to accomplish. Completion of each task takes them to a higher level in the game. In the beginning, tasks may be as simple as watching a horror film. As the levels progress, administrator of the game instructs the players to inflict harm on themselves. As proof, players also have to submit photographs of tasks completed. Committing suicide is the 50th task. Uptil now 130 teenagers have been reported to have died due to this game, the world over. These challenges point to the dark world of fun filled online games. Children see digital citizenship as 'fundamental to their well-being'. ${ }^{3}$ The boundary between online and off-line is often blurred for them and they tend to see digital access as a natural and integral part of their day to day existence and their fundamental right. ${ }^{4,5}$ Further, there is also vulnerability amongst adolescents. They have tendency to experiment and lack logical thinking.

Such challenges reach out to teenagers but may be dangerous to those who are part lonely, or is being bullied, dealing with self-esteem issues or trying to prove themselves. This is like playing a dare challenge. Once the adolescent gets into the flow of things, and reach the last few steps, rather than realizing the consequence of the step, the process takes over him.

There has been a spike in suicidal attempts by adolescents undergoing this challenge in India. In purview of this, some initiatives have been taken by the government. The government has directed the internet and social media giants Google, Facebook, WhatsApp, Instagram, Microsoft and Yahoo to immediately remove the links of the Blue Whale Challenge game. Guidelines for 'Safe and Effective Use of Internet and Digital Technologies in Schools and School Buses' by Central Board of Secondary Education (CBSE) have been issued to 18000 schools across the country. ${ }^{6}$ Other initiatives include sensitization of students, teachers and parents regarding the judicious use of internet and social media within the academic realms.

Unfortunately correction actions start late when some casualties have already happened. We need to develop mechanism to find out if similarly kind of games are existing or not and what needs to be done to those which are under process of development. Should we allow such games to develop and come in the market? What punitive mechanism do we have for companies which are manufacturing and promoting such games?

${ }^{1}$ Assistant Professor Department of Community Medicine, NDMC Medical College \& Hindu Rao Hospital New Delhi.

${ }^{2}$ Director Professor \& Head, Department of Community Medicine, VMMC \& Safdarjung Hospital New Delhi.

Correspondence: Dr. Tanu Anand, Department of Community Medicine, NDMC Medical College \& Hindu Rao Hospital New Delhi.

E-mail Id: drtanu.anand@gmail.com

Orcid Id: http://orcid.org/0000-0003-2911-2332

How to cite this article: Anand T, Kishore J.Blue Whale Challenge: Perplexing the teens' minds. Ind J Youth Adol Health 2017; 4(2): $1-2$.

Digital Object Identifier (DOI): https://doi.org/10.24321/2349.2880.201708

ISSN: $2349-2880$ 
Other preventive methods are health promotional in nature. We need to empower teens, parents and community to differentiate virtual world from real world. Our schools should be equipped with tools of monitoring of risk factors and engaging teens with health promotional activities.

To conclude, use of online internet games is increasing amongst the adolescents particularly in India. While the challenges may vary from 'Pokemon Go Craze' to Blue whale suicidal challenge, the crux remains that the adolescents' minds are getting affected in aspect negative. There is a need for more ways to handle internet content to protect young minds.

\section{References}

1. Govindappa L, Kasi S, Henry G. Internet use and risk taking behaviors among adolescents. Ind J Paediatr 2014; 81(9):949-49.
2. DSM-5 Development. American Psychiatric Association [Internet] 2015 [Accessed on 19th Aug, 2017]. Available from: http://www.dsm5.org/Documents/Internet\%20 Gaming\%20Disorder\%20Fact\%20Sheet.pdf.

3. Australian Human Rights Commission. Children's Rights Report 2014. Sydney: Human Rights Commission; 2014.

4. Ito M, Baumer S, Bittanti M, Boyd D, Cody R, HerrStephenson B, et al. Hanging out, messing around and geeking out: Kids living and learning with new media. Cambridge: The MIT Press; 2010.

5. Third A, Bellerose D, Dawkins U, Keltie E, Pihl K. Children's rights in the digital age: A download from children around the world. Melbourne: Young and Well Cooperative Research Centre; 2014.

6. CBSE. Guidelines for Safe and Effective Use of Internet and Digital Technologies in Schools and School Buses [Internet] 2017 [ Accessed on 2017, Aug 20]. Available from: http://cbseacademic.in/32_Circular_2017.pdf. 